\title{
Chronic Treatment with Combined Chemotherapeutic Agents Affects Hippocampal Micromorphometry and Function in Mice, Independently of Neuroinflammation
}

\author{
Sohi Kang ${ }^{1 \dagger}$, Sueun Lee ${ }^{1 \dagger}$, Juhwan Kim ${ }^{1}$, Jong-Choon Kim ${ }^{1}$, Sung-Ho Kim ${ }^{1}$, \\ Yeonghoon Son ${ }^{1,2}$, Taekyun Shin ${ }^{3}$, BuHyun Youn ${ }^{4}$, Joong-Sun Kim ${ }^{5}$, \\ Hongbing Wang ${ }^{6}$, Miyoung Yang ${ }^{7 *}$ and Changjong Moon ${ }^{1 *}$ \\ ${ }^{1}$ College of Veterinary Medicine and BK21Plus Project Team, Chonnam National University, Gwangju 61186, ${ }^{2}$ Primate \\ Resource Center, Korea Research Institute of Bioscience and Biotechnology (KRIBB), Jeongeup 56216, ${ }^{3}$ Department of \\ Veterinary Anatomy, College of Veterinary Medicine, Jeju National University, Jeju 63243, ${ }^{4}$ Department of Integrated Biological \\ Science, Pusan National University, Busan 46241, ${ }^{5}$ K-herb Research Center, Korea Institute of Oriental Medicine, Daejeon \\ 34054, Korea, ${ }^{6}$ Department of Physiology and Neuroscience Program, Michigan State University, MI 48824, USA, ${ }^{7}$ Department \\ of Anatomy, School of Medicine and Institute for Environmental Science, Wonkwang University, Iksan 54538, Korea
}

\begin{abstract}
Chemotherapeutic agents induce long-term side effects, including cognitive impairment and mood disorders, particularly in breast cancer survivors who have undergone chemotherapy. However, the precise mechanisms underpinning chemotherapy-induced hippocampal dysfunction remain unknown. In this study, we investigated the detrimental effects of chronic treatment with a combination of adriamycin and cyclophosphamide (AC) on the neuronal architecture and functions of the hippocampi of female C57BL/6 mice. After chronic AC administration, mice showed memory impairment (measured using a novel object recognition memory task) and depression-like behavior (measured using the tail suspension test and forced swim test). According to Golgi staining, chronic AC treatment significantly reduced the total dendritic length, ramification, and complexity as well as spine density and maturation in hippocampal neurons in a sub-region-specific manner. Additionally, the AC combination significantly reduced adult neurogenesis, the extent of the vascular network, and the levels of hippocampal angiogenesis-related factors. However, chronic AC treatment did not increase the levels of inflammation-related signals (microglial or astrocytic distribution, or the levels of pro-inflammatory cytokines or M1/M2 macrophage markers). Thus, chronic AC treatment changed the neuronal architecture of the adult hippocampus, possibly by reducing neurogenesis and the extent of the vasculature, independently of neuroinflammation. Such detrimental changes in micromorphometric parameters may explain the hippocampal dysfunction observed after cancer chemotherapy.
\end{abstract}

Key words: Chemotherapy, Hippocampus, Neurogenesis, Neuroinflammation, Neuronal architecture, Vasculature

Received August 21, 2018, Revised October 1,2018, Accepted October 2, 2018

* To whom correspondence should be addressed.

Changjong Moon, TEL: 82-62-530-2838,FAX: 82-62-530-2841,e-mail: moonc@chonnam.ac.kr

Miyoung Yang, TEL: 82-63-850-6758, FAX: 82-63-852-9115, e-mail: yangm@wku.ac.kr

"These authors contributed equally to this work. 


\section{INTRODUCTION}

The use of chemotherapy, which is the main therapeutic strategy for cancer, has led to a higher rate of survival among patients. However, anti-cancer agents have detrimental effects on the nervous system of cancer survivors [1], as they can cause acute alterations in consciousness, seizures, cerebral infarctions, paralysis, neuropathy, and ototoxicity [2]. Furthermore, several studies have reported that chemotherapy induces brain dysfunction (particularly, hippocampus-related cognitive impairment and mood disorders) in humans [3-5] and animal models [6-8]. Chemotherapyinduced brain dysfunction has been associated with several mechanisms, such as decreased adult neurogenesis, increased oxidative stress, damaged white matter, neuroinflammation, and reduced cerebral blood flow [9].

Cognitive impairment occurs in 16 50\% of patients receiving chemotherapy for breast cancer, and it persists in some patients (up to 10 years) even after complete remission [10, 11]. Although various chemotherapeutic agents are used alone or in combination to treat patients with breast cancer [12], the combination of adriamycin and cyclophosphamide (AC) is one of the most common adjuvant medications for breast cancer [13]. However, AC can disrupt the cognitive functioning of patients with breast cancer [5]. Indeed, a previous study using the passive avoidance test reported memory deficits in AC-treated mice [7]. Additionally, animals treated with $\mathrm{AC}$ showed hippocampal dysfunction on the contextual fear memory test [14]. These results indicate that AC treatment can damage the brain, resulting in memory impairment.

Previous work analyzing the structure of mature hippocampal neurons has identified several stimuli, such as irradiation [15] and stress [16], that elicit marked alterations in dendritic complexity, spine density, and synaptic plasticity-related protein levels. These micromorphometric alterations were temporally coincident with impaired cognition [17] and depression-like behavior [18], suggesting an interaction between altered neuronal architecture and hippocampal functioning. Recent studies have demonstrated that chronic chemotherapy induces morphological changes in the neurons of the cingulate cortex and hippocampus $[19,20]$. Specifically, the densities of dendritic spines and arborizations were significantly reduced in the cingulate cortical neurons of chronic cisplatin-treated mice [19]. Moreover, chronic cyclophosphamide treatment induced deficits in learning and memory and decreased dendritic arborization in the mouse hippocampus [20]. Thus, these neuroanatomical studies suggest that chemotherapy-induced changes in neuronal morphology may be related to hippocampal dysfunction. However, further studies are needed to understand the correlations between the architecture of hippocampal neurons and hippocampal dysfunction and to clarify the mechanisms underlying these associations.

Neuroinflammation is considered to be the most important trigger of hippocampal dysfunction. A clinical study found that breast cancer patients under chronic treatment with doxorubicin-based chemotherapy exhibited a decreased left-side hippocampal volume, poor memory, and increased levels of the pro-inflammatory cytokines interleukin (IL)-6 and tumor necrosis factor-alpha (TNF)- $\alpha$ [21]. In addition, several animal studies have revealed an important role for neuroinflammation in terms of dendritic spine structure. Increased cytokine levels inhibited the maintenance of dendritic spines either directly or indirectly, impairing hippocampus-dependent behaviors [22, 23]. However, other studies suggested that hippocampal dysfunction and neuroinflammation were not linked. Son et al. [24] reported hippocampal dysfunction in the chronic phase after cranial irradiation, with concomitant microglial reduction, suggesting that neuroinflammation was not always necessary for/related to alterations in hippocampal function. Thus, any effect of neuroinflammation on hippocampal dysfunction remains controversial and more detailed analysis is required on the outcomes of chronic chemotherapy.

This study evaluated the effects of chronic treatment with clinically relevant doses and schedules of the AC combination in disease-free mice. First, we performed hippocampus-related behavioral tests to evaluate hippocampal dysfunction, including cognitive deficits and depression-like behavior, examining changes in the neuronal architecture (i.e., dendritic complexity and arborization and spine density and morphology) in the hippocampus. Additionally, changes in the rates of adult neurogenesis and vascular network formation, and in the levels of angiogenesis- and inflammatory-related signals in the hippocampus after chronic AC treatment were also evaluated.

\section{MATERIALS AND METHODS}

\section{Subjects}

Female 7-week-old C57BL/6 mice purchased from DaihanBiolink Co. (Chungbuk, Korea) were quarantined and acclimatized for 1 week before the experiments were performed. The animals were housed in a room maintained at $23 \pm 2^{\circ} \mathrm{C}$, with a relative humidity of $50 \pm 5 \%$, under artificial lighting from $07: 00$ to 19:00 h, with 13 18 changes in air volume per hour. Animals had ad libitum access to tap water and commercial rodent chow (Jeil Feed Co., Daejeon, Korea). The Institutional Animal Care and Use Committee of Chonnam National University approved the study protocol (CNU IACUC-YB-2016-27), and the experiments were conducted in accordance with the internationally accepted prin- 
ciples for laboratory animal use and care dictated by the guidelines of the National Institutes of Health. Every effort was made to minimize the number of animals used and their suffering.

\section{Chemotherapeutic regimen}

After acclimatization, mice were randomly assigned to either the chemotherapy ( $n=23)$ or the vehicle control $(n=23)$ group. Mice in the chemotherapy group received a combination of adriamycin (doxorubicin, $2 \mathrm{mg} / \mathrm{kg}$; Sigma-Aldrich, St. Louis, MO, USA) and cyclophosphamide (50 mg/kg; Sigma-Aldrich) dissolved in normal saline. Mice in the control group received an equal volume of normal saline to control for the effects of stress induced by the injection. Animals in all groups received one injection per week for 4 consecutive weeks (Fig. 1A for study time line). The dosages selected were based on our preliminary work and other previous studies [25,26], which showed that animals tolerated these doses with minimal weight loss and death (Fig. 1B). Body weight was measured at baseline and every week during the experiments to confirm the absence of any major peripheral toxicities that might influence behavior tests.

\section{Open field}

To evaluate the effect of chemotherapy on locomotor activity, the open-field test was administered one week after the final injection. Various parameters including ambulatory movement time $(\mathrm{sec})$, ambulatory moving distance $(\mathrm{cm})$, center time $(\mathrm{sec})$, and center distance $(\mathrm{cm})$, were determined over $30 \mathrm{~min}$ with the ad of a TruScan Photo Beam Activity System (Coulbourn Instruments, Whitehall, PA, USA).

\section{Tail suspension test (TST)}

The TST performed in this study was similar to that described previously [24]. Briefly, mice were suspended from a plastic rod mounted $50 \mathrm{~cm}$ above the surface by fastening their tail to the rod with adhesive tape. Immobility, defined as the absence of any limb or body movements except for those caused by respiration, was measured for $6 \mathrm{~min}$.

\section{Forced swim test (FST)}

The FST performed in this study was similar to that described previously [24]. Briefly, mice were gently placed in a clear plastic cylinder with a diameter of $13 \mathrm{~cm}$ and height of $23 \mathrm{~cm}$ that was filled with $10 \mathrm{~cm}$ clear water at $23 \sim 25^{\circ} \mathrm{C}$. The test duration was $6 \mathrm{~min}$, and immobility was measured during the last $4 \mathrm{~min}$. Immobility was defined as the absence of any horizontal or vertical movement in the water, excluding the minor movements required for the mouse to keep its head above the surface. The water was replaced before each animal began the test.

\section{Novel object recognition memory (ORM) task}

Mice were individually habituated to an acrylic chamber $(42 \times 28 \times 20 \mathrm{~cm})$ for 3 consecutive days. Immobile plastic objects $3.5 \mathrm{~cm}$ in height and differing in shape were used in the recognition test. The chamber and all objects were cleaned with 70\% (v/ v) ethanol between trials to prevent buildup of olfactory cues. During training, two randomly selected differently shaped objects were presented to each mouse for $10 \mathrm{~min}$. At $24 \mathrm{~h}$ after training, another set of objects (one previously presented object and one novel object) was presented to trained mice. An interaction was scored when each mouse sniffed or touched an object or moved toward an object in such a way that the distance between the tip of its nose and the object was less than $1 \mathrm{~cm}$. We assumed that if the mouse retained the memory of a previously encountered object, the animal would prefer the novel object. Each preference rate was defined as the number of interactions with a specific object divided by the total number of interactions with either object. Any

A



B

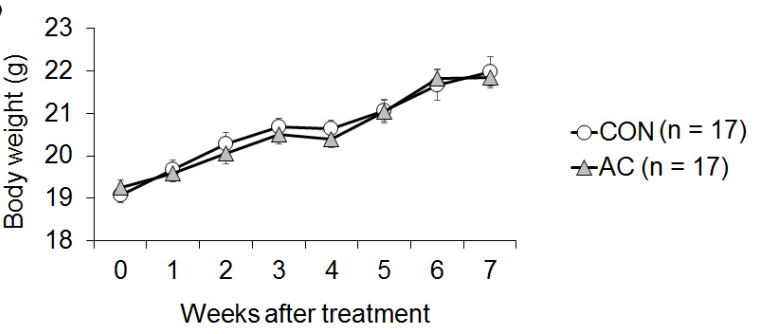

Fig. 1. Schematic diagram of the experimental procedure and linear graphs of body weight changes. (A) Mice received one intraperitoneal injection per week of vehicle or AC for 4 consecutive weeks (syringes); this was followed 2 days later by six consecutive daily injections of BrdU. OFT, open field test; ORM, novel object recognition memory task; TST, tail suspension test; FST, forced swim test. (B) Animals in all groups gained weight over the course of the study, as expected on the basis of their starting age of 2 months. Mice treated with AC tended to same weight-gain tendency over the course of the study compared to vehicletreated animals. No significant differences were observed between vehicle- and AC-treated mice in the rate of weight gain. Data are expressed as means \pm SEs. 
preference for exploring a novel object was measured by estimating individual discrimination ratios (the difference between the number of approaches to the novel and the familiar objects divided by the total number of approaches to both objects).

\section{Golgi staining}

Golgi impregnation was used to quantify the number of dendritic spines in the hippocampi. The FD Rapid Golgistain ${ }^{\mathrm{TM}}$ Kit and associated methodology was utilized (FD Neurotechnologies, Ellicott City, MD, USA). Brains were rinsed in $0.1 \mathrm{M}$ phosphate buffer, immersed in Golgi-Cox solution for 14 days, and then transferred to a sucrose-containing solution at RT for 3 7 days. The hippocampi were sectioned at $200 \mu \mathrm{m}$ and apposed to gelatincoated slides with a drop of sucrose solution. Slides were left to air dry at RT for 3 days in the dark, then processed for Golgi impregnation as outlined in the FD Rapid Golgistain ${ }^{\mathrm{TM}}$ Kit.

\section{Sholl analysis}

For dendritic branching analysis, all selected neurons had to satisfy the following criteria: 1) the cell body had to be located within the area of interest; 2) the neuron had to be well-impregnated and the length of the branch unbroken; and 3) the branches had to be relatively isolated from the neighboring neurons to avoid interfering with the analysis [27]. Five neurons from each brain region in each animal were drawn using a camera lucida at a magnification of 400×. Dendrites in each of the selected neurons were quantitatively analyzed using Sholl's concentric circle method [28]. A series of concentric rings, spaced $10 \mu \mathrm{m}$ apart, were placed over the neuron and centered on the cell body, and the number of dendrites intersecting each circle in the series of concentric circles was counted to estimate the total dendritic length, branch points, and dendritic complexity.

\section{Analysis of dendritic spine density and morphology}

To analyze the dendritic spine morphology distribution, unbranched, unbroken, and consistently stained dendritic segments were selected. All visible flanking spines were counted along 30$\mu \mathrm{m}$ terminal-tip segments of three segments from each neuron at a magnification of $1500 \times$. Spines were classified into the following categories based on morphology: 1) thin: spines with a long neck and visible small head;2) mushroom: large spines with a welldefined neck and a very voluminous head; and 3) stubby: very short spines without a distinguishable neck and with a stubby appearance [29]. Nine segments were counted in each animal, and spine density was calculated as the number of spines per $10 \mu \mathrm{m}$ dendritic length.

\section{Bromodeoxyuridine (BrdU) treatment and immunohisto- chemistry}

To assess the impact of chemotherapy on hippocampal neurogenesis, BrdU (100 mg/kg intraperitoneally; Sigma-Aldrich) was administered for 6 consecutive days beginning 2 days after the final drug injection. Three weeks later, animals were sacrificed for tissue sampling. Brains were removed and post-fixed with $4 \%$ (w/ v) paraformaldehyde in phosphate-buffered saline (PBS). Next, the brains were suspended in $30 \%(\mathrm{w} / \mathrm{v})$ sucrose for 4 days. Brains were sectioned into $30-\mu \mathrm{m}$-thick slices in the sagittal plane using a sliding microtome (SM2010R; Leica Microsystems, Wetzlar, Germany) and stored in PBS at $4^{\circ} \mathrm{C}$.

Free-floating slices were treated with $1 \mathrm{~N} \mathrm{HCl}$ for $10 \mathrm{~min}$ on ice and $2 \mathrm{~N} \mathrm{HCl}$ for $30 \mathrm{~min}$ at $37^{\circ} \mathrm{C}$ followed by three 5 -min washes in $0.1 \mathrm{M}$ Borate buffer $\mathrm{pH}$ 8.5. Slices were washed extensively in PBS and blocked with 2\% (v/v) normal goat serum (Vector Laboratories, Burlingame, CA, USA) in $0.3 \%(\mathrm{v} / \mathrm{v})$ Triton X-100 for $1 \mathrm{~h}$ at room temperature (RT). Next, the sections were incubated with primary antibodies, rabbit anti-BrdU (1:500; Abcam, Cambridge, MA, UK) in antibody dilution buffer (Invitrogen, Carlsbad, CA, USA), for 2 days overnight at $4^{\circ} \mathrm{C}$. After washing, sections were reacted with biotinylated rabbit anti-rat IgG (Vector ABC Elite Kit; Vector Laboratories) for $2 \mathrm{~h}$ at $\mathrm{RT}$ and then washed and incubated for $1 \mathrm{~h}$ at RT with an avidin-biotin peroxidase complex (Vector ABC Elite Kit; Vector Laboratories) prepared according to the manufacturer's instructions. After washing, the peroxidase reaction proceeded using a diaminobenzidine substrate (contained in the DAB kit; Vector Laboratories) prepared according to the manufacturer's instructions.

\section{Immunohistochemistry of free-floating sections}

Free-floating sections were incubated in $0.3 \%(\mathrm{v} / \mathrm{v})$ hydrogen peroxide in distilled water for $20 \mathrm{~min}$ to inactivate endogenous peroxidase activity and blocked with 5\% (v/v) normal rabbit serum or normal goat serum (Vector ABC Elite Kit; Vector Laboratories) in $0.3 \%(\mathrm{v} / \mathrm{v})$ Triton X-100 with goat or rabbit antibodies, respectively. Blocking proceeded for $1 \mathrm{~h}$ at RT. Sections were next incubated with primary antibodies, goat anti-doublecortin (DCX; 1:1,600; Santa Cruz Biotechnology, Santa Cruz, CA, USA), rabbit anti-von Willebrand factor (vWF; 1:500; Abcam), rabbit antiIba1(1:1,000; Wako, Osaka, Japan), or rabbit anti-glial fibrillary acidic protein (GFAP; 1:2,000 dilution, Dako, Glostrup, Denmark) in antibody dilution buffer (Invitrogen) overnight at $4^{\circ} \mathrm{C}$. After washing, sections were reacted with biotinylated rabbit anti-goat IgG or goat anti-rabbit IgG (Vector ABC Elite Kit; Vector Laboratories) for $1 \mathrm{~h}$ at RT, washed, and incubated for $1 \mathrm{~h}$ at RT with an avidin-biotin peroxidase complex (Vector ABC Elite Kit; Vector 
Laboratories) prepared according to the manufacturer's instructions. After washing, the peroxidase reaction proceeded using a diaminobenzidine substrate (contained in the DAB kit; Vector Laboratories) prepared according to the manufacturer's instructions. As a control, the primary antibodies were omitted for a few test sections in each experiment (data not shown).

\section{Analysis for immunohistochemically stained sections}

Immunohistochemically stained images were captured using a BX-40 microscope (Olympus, Tokyo, Japan) fitted with an eXcope X3 camera (DIXI Optics, Daejeon, Korea). To quantify BrdU and DCX immunoreactivities, a standard counting area included the DG regions in three non-overlapping sections (approximately 300 $\mu \mathrm{m}$ apart) were chosen for each animal. All positively immunolabeled cells within the subgranular zone of the supra- and inflapyramidal blades of the DG were counted. All counts were performed by the same individual who was blinded to experimental conditions. The mean number of immunopositive cells from three sections of each mouse was assigned a value of 1 . The number per group was averaged and expressed as the mean \pm standard error (SE).

To evaluate the intensity for immunoreactivities of vWF, Ibal, and GFAP, the images were converted to grayscale, and the threshold on every tissue was comparably adjusted by background subtraction. The control stained tissue sections (absence of primary antibodies) were utilized for using one threshold on all slides in the analysis for additional correction. The mean gray value (256 gray levels) for each selected area was determined using ImageJ software (NIH, Bethesda, MD, USA). Three non-overlapping sections (approximately $300 \mu \mathrm{m}$ apart) were chosen from each animal, and the intensities in the CAl and granular cell layer of DG were measured. All measurements were performed by the same individual who was blinded to the experimental conditions. The mean intensity of the control was assigned a value of 1 , and the relative changes in intensity levels were expressed as the relative optical densities (OD) of vWF, Ibal, and GFAP. The relative OD per group was averaged and expressed as the mean \pm SE.

\section{Western blotting}

The Western blotting method performed in this study was similar to that described previously [30]. The hippocampi were individually and rapidly immersed in buffer $\mathrm{H}(50 \mathrm{mM}$ $\beta$-glycerophosphate, $1.5 \mathrm{mM}$ ethylene glycol tetraacetic acid, 0.1 $\mathrm{mM} \mathrm{Na} \mathrm{VO}_{4}, 1 \mathrm{mM}$ dithiothreitol, $10 \mu \mathrm{g} / \mathrm{ml}$ aprotinin, $2 \mu \mathrm{g} / \mathrm{ml}$ pepstatin, $10 \mu \mathrm{g} / \mathrm{ml}$ leupeptin, $1 \mathrm{mM}$ phenylmethanesulfonyl fluoride; pH 7.4) and sonicated for $8 \mathrm{~s}$. Next, sodium dodecyl sulfate (SDS) sample buffer $(4 \times)$ was added to each homogenized sample prior to heating at $100^{\circ} \mathrm{C}$ for $10 \mathrm{~min}$, and proteins were separated by SDS polyacrylamide gel electrophoresis (4 12\% (w/ v) bis-tris gel; Novex, San Diego, CA, USA). The resolved proteins were transferred to polyvinylidene difluoride membranes, which were subsequently blocked with $1 \%(\mathrm{v} / \mathrm{v})$ normal goat serum and $0.5 \%(\mathrm{v} / \mathrm{v})$ fetal bovine serum in PBS containing $0.1 \%(\mathrm{v} / \mathrm{v})$ Tween 20 (PBS-T; pH 7.4) for $1 \mathrm{~h}$ at RT. The membranes were next incubated in PBS-T overnight at $4^{\circ} \mathrm{C}$ with either mouse anti-vascular endothelial growth factor (VEGF; 1:1,000; Santa Cruz Biotechnology), goat anti-erythropoietin (EPO; 1:1,000; Santa Cruz Biotechnology), rabbit anti-Ibal(1:1,000; Wako), or mouse antiGFAP (1:1,000; Sigma-Aldrich) primary antibody. After extensive washing and incubation with horseradish peroxidase-conjugated anti-mouse, goat, or rabbit antibody (1:10,000; Thermo Fisher Scientific, Waltham, MA, USA), signals were visualized using a chemiluminescence kit (SuperSignal West Pico; Thermo Fisher Scientific). For normalization purposes, the membranes were re-probed with mouse anti- $\beta$-actin primary antibody $(1: 10,000$; Sigma-Aldrich) for $2 \mathrm{~h}$ at RT. The optical density (OD; per $\mathrm{mm}^{2}$ ) of each band was measured using the C-DiGit Blot Scanner 3600 (Li-Cor, Lincoln, NE, USA), and the ratio of the density of each band relative to that of $\beta$-actin was compared using Image J software (National Institutes of Health, Bethesda, MD, USA). The mean intensity of the control was assigned a value of 1 , and relative changes in the intensity levels of each sample were expressed as the relative OD. The relative OD per group was averaged and expressed as the mean \pm SE.

\section{RNA extraction and cDNA synthesis}

Total hippocampal RNA was isolated using RNeasy lipid tissue mini-kits (Qiagen, Valencia, CA, USA) according to the manufacturer's instructions. RNA concentrations were quantified via optical densitometry using a NanoDrop ND-1000 spectrophotometer (Thermo Fisher Scientific). First-strand complementary DNA (cDNA) was prepared with the aid of random primers (Takara Bio Inc., Tokyo, Japan) and Superscript II reverse transcriptase (Invitrogen) according to the manufacturer's instructions. cDNA samples were diluted to $8 \mathrm{ng} / \mu \mathrm{L}$ in RNase-free water and stored at $-80^{\circ} \mathrm{C}$.

\section{Quantitative reverse transcription polymerase chain reaction}

Quantitative reverse transcription polymerase chain reaction (qRT-PCR) amplifications were performed using TOPreal qPCR $2 \times$ PreMIX SYBR Green kits (Enzynomics, Daejeon, Korea) and a Stratagene MX3000P platform (Agilent Technologies, Santa Clara, CA, USA) according to the manufacturer's instructions. The thermal cycling profile consisted of preincubation at $94^{\circ} \mathrm{C}$ for $10 \mathrm{~min}$, 
Table 1. Primer sequences for qRT-PCR analysis

\begin{tabular}{|c|c|c|c|}
\hline Gene & Accession No. & & Primer sequence \\
\hline \multirow[t]{2}{*}{ Arc } & NM_018790.3 & FWD & 5'-GATCTTTCCTGCTGTGCCCT-3' \\
\hline & & RVS & 5'-CGCAACAAGGCCTACTCAGA-3' \\
\hline \multirow[t]{2}{*}{ TNF- $a$} & NM_013693.2 & FWD & 5'-CATCTTCTCAAAATTCGAGTGACAA-3' \\
\hline & & RVS & 5'-TGGGAGTAGACAAGGTACAACCC-3' \\
\hline \multirow[t]{2}{*}{ IL-6 } & NM_031168.1 & FWD & 5'-TGGAGTCACAGAAGGAGTGGCTAAG-3' \\
\hline & & RVS & 5'-TCTGACCACAGTGAGGAATGTCCAC-3' \\
\hline \multirow[t]{2}{*}{ IL- $1 \beta$} & NM_008361.3 & FWD & 5'-CTCGCAGCAGCACATCAACAAG-3' \\
\hline & & RVS & 5'-CCACGGGAAAGACACAGGTAGC-3' \\
\hline \multirow[t]{2}{*}{ iNOS } & NM_010927.0 & FWD & 5'-TTGAAATCCCTCCTGATCTTGT-3' \\
\hline & & RVS & 5'-TCACAGAAGTCTCGAACTCCAA-3' \\
\hline \multirow[t]{2}{*}{ CD206 } & NM_008625.1 & FWD & 5'-ACGACAATCCTGTCTCCTTTGT-3' \\
\hline & & RVS & 5'-TCAGCTTTGGTTGTAATGGATG-3' \\
\hline \multirow[t]{2}{*}{ GAPDH } & NM_008084.2 & FWD & 5'-TCCATGACAACTTTGGCATT-3' \\
\hline & & RVS & 5'-GTTGCTGTTGAAGTCGCAGG-3' \\
\hline
\end{tabular}

qRT-PCR, quantitative real-time reverse transcription polymerase chain reaction; GAPDH, glyceraldehyde-3-phosphate dehydrogenase; FWD, forward; RVS, reverse.

followed by 45 cycles of denaturation $\left(94^{\circ} \mathrm{C}, 15 \mathrm{~s}\right)$, annealing $\left(55^{\circ} \mathrm{C}\right.$, $30 \mathrm{~s})$, and elongation $\left(72^{\circ} \mathrm{C}, 20 \mathrm{~s}\right)$. Melting curves were subsequently produced by heating the products at $94^{\circ} \mathrm{C}$ for $15 \mathrm{~s}$, cooling to $50^{\circ} \mathrm{C}$ for $30 \mathrm{~s}$, and then slowly heating to $94^{\circ} \mathrm{C}$ in $0.5^{\circ} \mathrm{C}$ increments. Melting-curve analyses confirmed that only single products were amplified. The primer sequences used for qRT-PCR are shown in Table 1. All data readings were normalized to the amplifications of the reference gene glyceraldehyde-3-phosphate dehydrogenase (GAPDH) and the reference dye included in the SYBR master mix. The cycle-at-threshold $(\mathrm{Ct})$ method was used to calculate mRNA expression levels, and the results expressed as -fold changes compared to the control, employing the $2^{-\Delta \Lambda} \mathrm{CT}$ method.

\section{Cytokine analyses}

Cytokine levels were determined using the Luminex fluorescentbead mouse cytokine assay panel (Milliplex ${ }^{\circledR}$ Map; Millipore, Bedford, MA). The levels of TNF- $\alpha$, IL- 6 , and IL- $1 \beta$ were measured in the sera and hippocampi of vehicle- and AC-treated mice. Briefly, samples were incubated with the bead mixture overnight at $4^{\circ} \mathrm{C}$. After washing, the beads were incubated with detection antibodies for $1 \mathrm{~h}$ at RT, followed by incubation with the streptavidinphycoerythrin reagent for $30 \mathrm{~min}$. Data were evaluated with the aid of Luminex 200 (Luminex, Austin, TX, USA) and Masterplex QT 2010 (Hitachi Solutions America, Ltd., South San Francisco, CA, USA) software. Standard curves were generated using known concentrations of mouse cytokines.

\section{Statistical analysis}

The data are presented as means \pm SEs. The results were analyzed to identify differences between the vehicle control and anti-cancer agent treatment groups using two-tailed Student's t-tests performed on the SPSS 23 (SPSS, Chicago, IL, USA). In all analyses, a p-value less than 0.05 was considered to indicate statistical significance.

\section{RESULTS}

\section{Chronic AC treatment did not affect locomotor activity}

Basic locomotor activity in a novel environment was performed via open-field analysis (Fig. 2), because alterations in exploratory activity in such an environment may influence behavior during performance of ORM task, TST, and FST (Fig. 3). Open-field analysis quantifies overall activity levels that may reflect motivation and the ability to perform tasks. No difference in ambulatory movement time, ambulatory distance, center time, or center distance, was evident between vehicle-treated and AC-treated mice (Fig. 2), indicating that AC treatment did not alter locomotor activity, which, again could not affect behavioral test results in this study.

\section{Chronic AC treatment impaired novel ORM}

We examined ORM 10 days after the last injection to evaluate hippocampus-related cognitive deficits in adult mice after chronic AC treatment (Fig. 1A). During the training session, the number of interactions with each object did not differ between the vehicletreated and AC-treated mice, reflecting normal motivation and exploratory activity ( $\mathrm{t}(32)=0.701, \mathrm{p}=0.489$; Fig. $3 \mathrm{~A}$ left). Twentyfour hours after the training sessions, novel object recognition was assessed in the mice. The vehicle-treated mice showed a preference for the novel object; however, the AC-treated mice exhibited a 

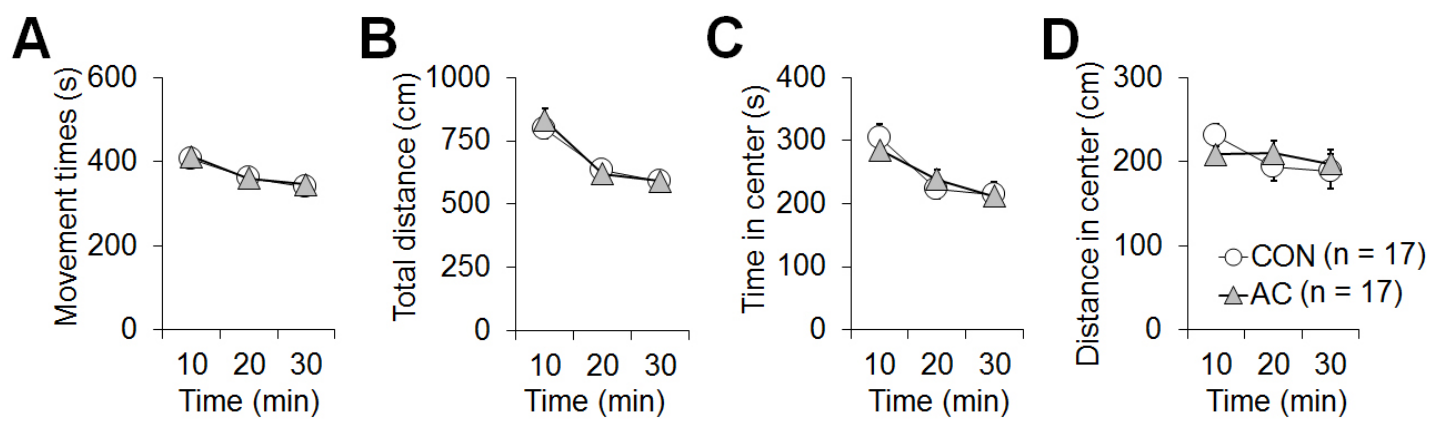

Fig. 2. Chronic AC treatment did not affect basal locomotor activity. None of total movement time (A), total traveled distance (B), center time (C), or center distance (D) differed between vehicle-treated and AC-treated mice. Data are expressed as means \pm SEs.

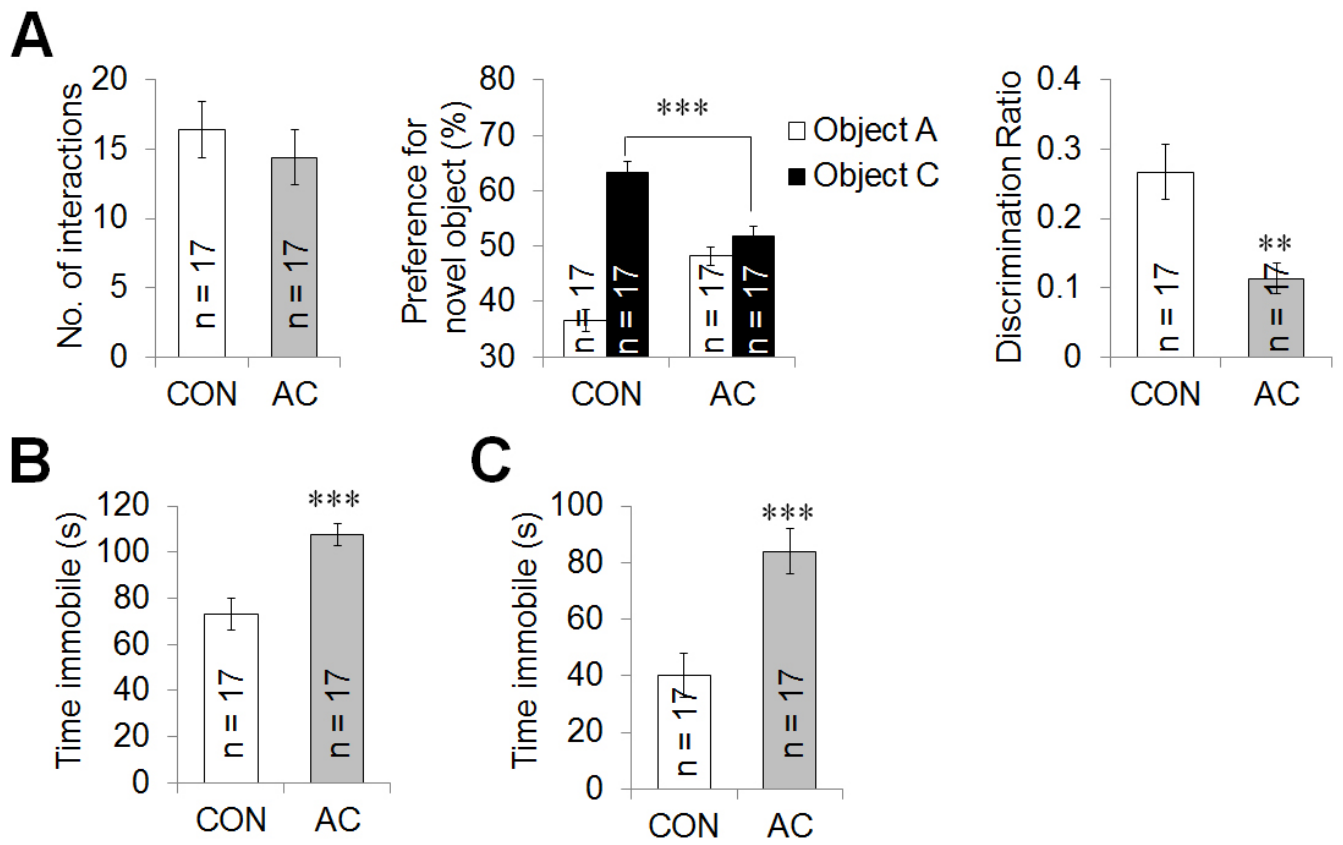

Fig. 3. AC affected hippocampus-related animal behavior. (A left) In the ORM training, both groups exhibited equal preference levels for the two test objects. (A middle) Upon testing, vehicle-treated mice preferred the novel object, but AC-treated mice were impaired in terms of novel object recognition. (A right) The discrimination ratio was markedly lower in AC-treated mice than vehicle-treated mice, indicating that the anti-cancer treatment impaired novel object preference. (B, C) AC-treated mice were immobile for significantly more time than were vehicle-treated control mice during the TST (B) and FST (C), which evaluate depression-like behavior. These results indicate that AC treatment induced depression-like behavior. Data are expressed as means \pm SEs. ${ }^{* *} \mathrm{p}<0.01,{ }^{* * *} \mathrm{p}<0.001$ vs. vehicle-treated controls.

lower preference ( $\mathrm{t}(32)=4.461, \mathrm{p}<0.001$; Fig. 3 A middle). Statistical analysis of the between-group discrimination ratios indicated that the difference between the vehicle- and the AC- treated mice was significant $(t(32)=3.429, p<0.01$; Fig. 3 A right $)$, indicating that the memory and learning of AC-treated mice were impaired.

\section{Chronic AC treatment induced depression-like behaviors}

The TST and FST, which are also hippocampus-related behavioral paradigms [24], are useful for assessing depression-like behavior and antidepressant activity. The vehicle-treated and AC- treated mice were examined using the TST and FST at 14 and 17 days, respectively, following the last injection (Fig. 1A). AC-treated mice exhibited a longer duration of immobility during the TST compared with the vehicle-treated mice $(t(32)=-4.011, \mathrm{p}<0.001$; Fig. 3B). Similarly, the immobility time in the FST increased significantly in the AC-treated mice compared to the vehicletreated control group 17 days after the last injection $(\mathrm{t}(32)=-3.896$, $\mathrm{p}<0.001$; Fig. 3C), indicating that chronic AC treatment induced depression-like behaviors. 


\section{Chronic AC treatment significantly reduced total dendritic} complexity in the CA1 apical and dentate gyrus (DG) areas

Chronic AC treatment significantly reduced the total dendritic length in neurons in the hippocampal CA1 apical $(\mathrm{t}(48)=2.304$, $\mathrm{p}<0.05$; Fig. 4A, B left) and DG areas $(\mathrm{t}(48)=3.481, \mathrm{p}<0.01$; Fig. $4 \mathrm{C}, \mathrm{D}$ left). However, the total lengths of the CAl basal dendrites in the vehicle- and AC-treated groups did not differ significantly $(\mathrm{t}(48)=0.629, \mathrm{p}=0.532$; Fig. 4B left). Additionally, the number of branching points in the DG was reduced significantly following chronic AC treatment $(\mathrm{t}(48)=2.486, \mathrm{p}<0.05$; Fig. $4 \mathrm{D}$ middle). This tendency was also observed in the CA1 apical dendrites, although it did not reach statistical significance $(\mathrm{t}(48)=1.281, \mathrm{p}=0.206$; Fig. $4 \mathrm{~B}$ right).

We examined data from a Sholl analysis to quantify the number of dendritic intersections at different radial distances from the soma in the adult mouse hippocampus. The dendritic intersections in all areas examined were located at varying radial distances from the soma. The apical dendrites in the CA1 of AC-treated hippocampi exhibited fewer intersections than did those in the CA1 of vehicle-treated hippocampi at Sholl radii of 100 110 and $150 \sim 170 \mu \mathrm{m}$ from the soma (Fig. 4A, B lower). However, the number of dendritic intersections in the basal dendrites of the CA1 did
A

CA1

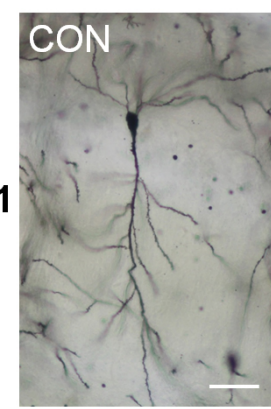

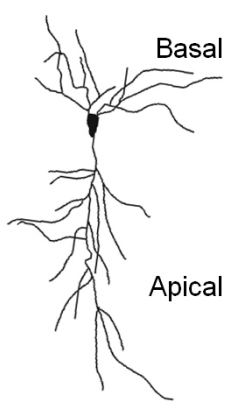
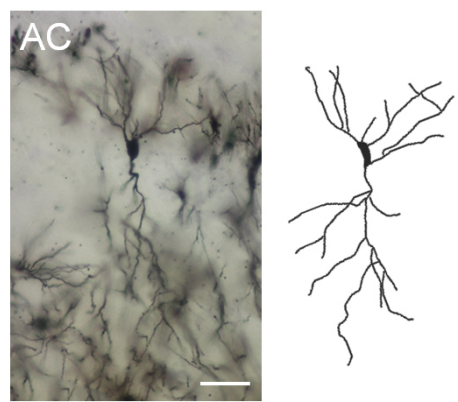

B

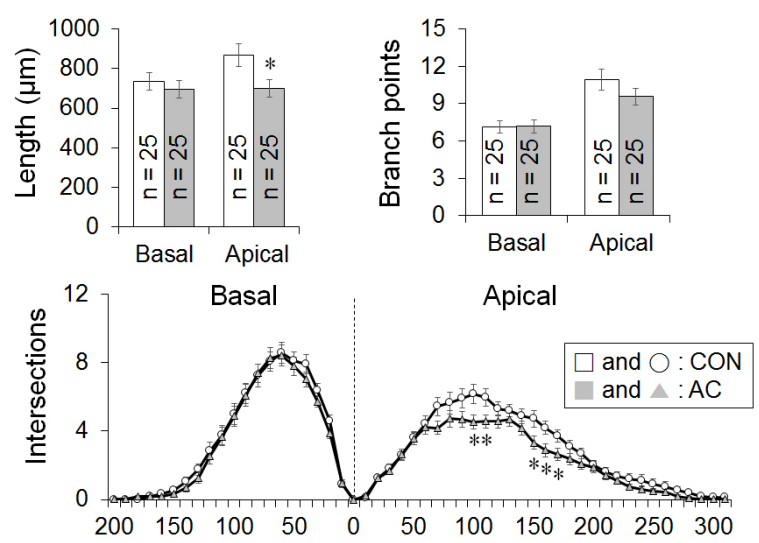

C

DG
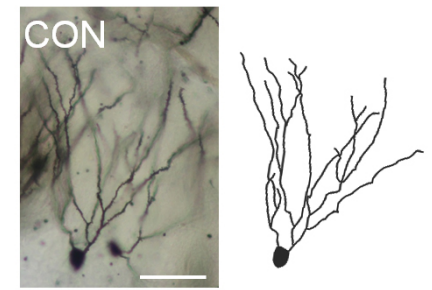
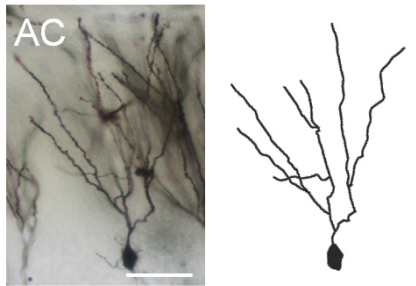

D

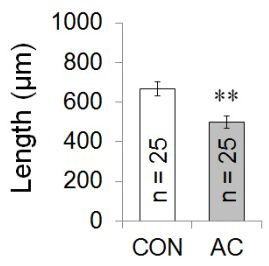

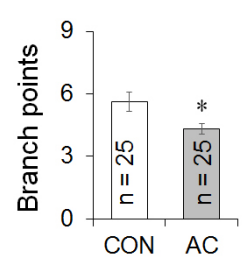

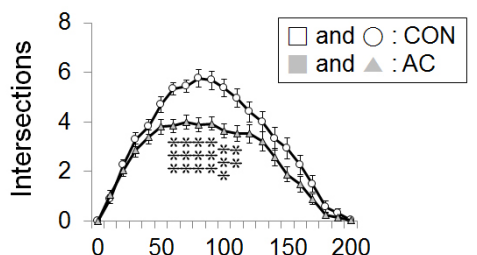

Fig. 4. AC affected dendritic complexity in the CA1 pyramidal cells and DG granule cells. Golgi staining of brains from vehicle- or ACtreated mice revealed consistent differences. (A) CAl pyramidal cells. (B) Bar graphs (left and right) showed the mean total dendritic length and dendritic branch points, respectively. Line graphs (lower) showed the mean number of intersections per $10-\mu \mathrm{m}$ radial unit distance from the soma (0) for basal (left) and apical (right) dendrites, indicating that $\mathrm{AC}$ reduced total dendritic complexity in the hippocampal CAl area. (C) DG granule cells. (D) Bar graphs (left and middle) showed the mean total dendritic length and dendritic branch points, respectively. Line graphs (right) showed the mean number of intersections per $10-\mu \mathrm{m}$ radial unit distance from the soma (0) for dendrites, indicating that AC reduced the total dendritic length and complexity in the DG granule cells. Data are expressed as means \pm SEs. ${ }^{*} \mathrm{p}<0.05,{ }^{* *} \mathrm{p}<0.01$, and ${ }^{* * *} \mathrm{p}<0.001$ vs. vehicle-treated controls. Scale bars in $(\mathrm{A})$ and (C) represent $60 \mu \mathrm{m}$. 
not differ between the vehicle- and AC-treated groups (Fig. 4A, B lower). In the DG, the granule cell dendrites in AC-treated hippocampi exhibited significantly fewer intersections than did those in vehicle-treated hippocampi at a Sholl radius of $60 \sim 110 \mu \mathrm{m}$ from the soma (Fig. 4C, D right).
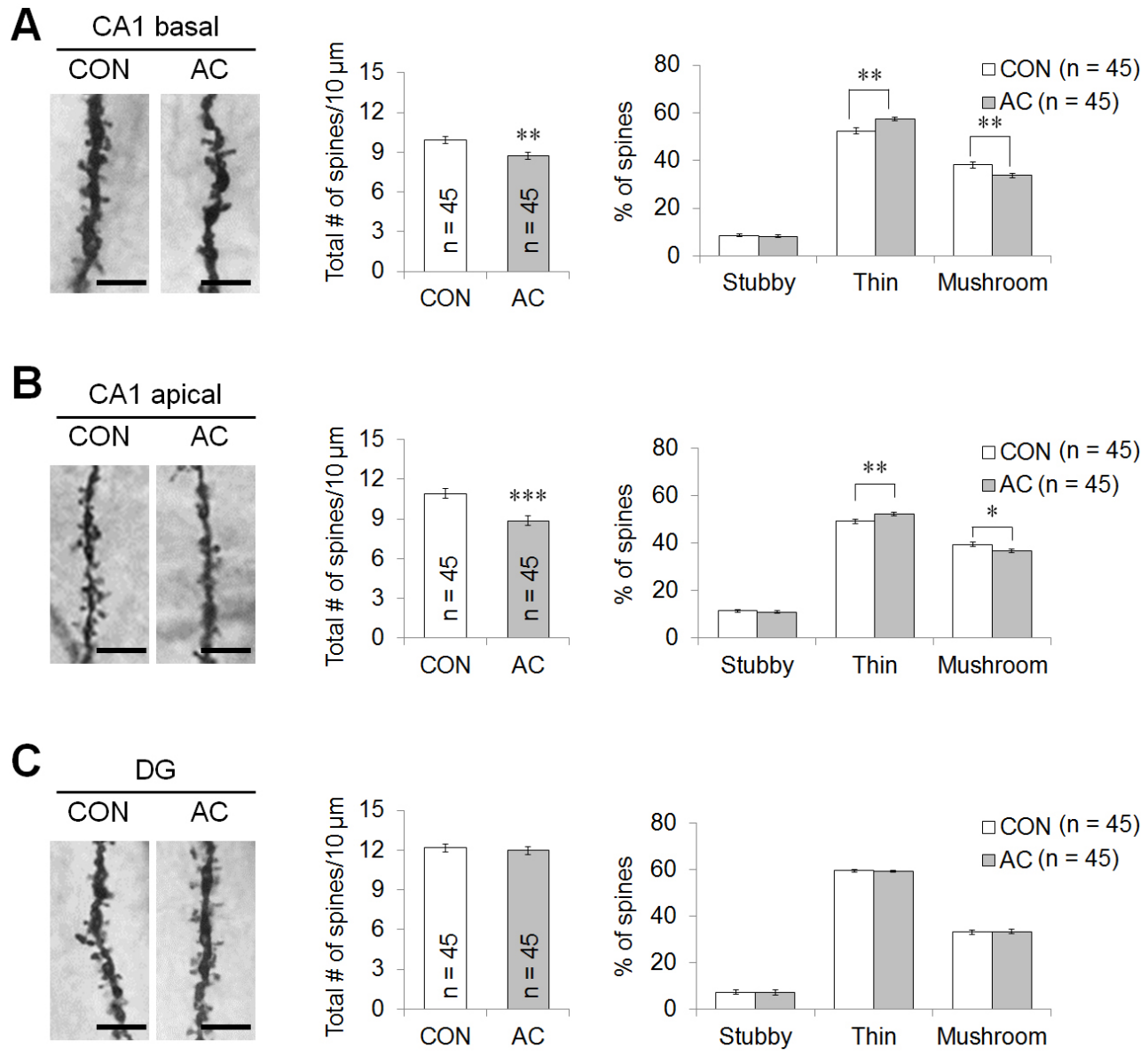

D

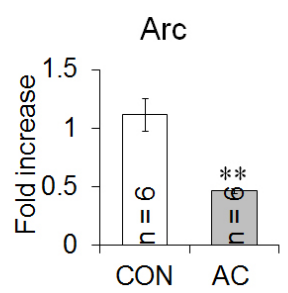

Fig. 5. AC affected dendritic spine density and morphology in the hippocampal CA1 and DG areas. Representative images from each cohort showing dendritic spines along Golgi-impregnated neurons. (A) CA1 basal dendrite. (B) CA1 apical dendrite. (C) DG dendrite. Bar graphs (middle) showed the mean total number of spines, indicating that AC reduced spine density in the CA1 dendritic area. Bar graphs (right) showed the mean proportion of spine morphological subtypes, indicating that AC reduced the proportion of mature spines in the CAl dendritic area. (D) Changes in the mRNA expression of Arc. The level of Arc mRNA significantly reduced following chronic AC treatment. Data are expressed as means \pm SEs. ${ }^{*} \mathrm{p}<0.05$, ${ }^{* *} \mathrm{p}<0.01$, and ${ }^{* * *} \mathrm{p}<0.001$ vs. vehicle-treated controls. Scale bars in the dendritic images represent $5 \mu \mathrm{m}$. 

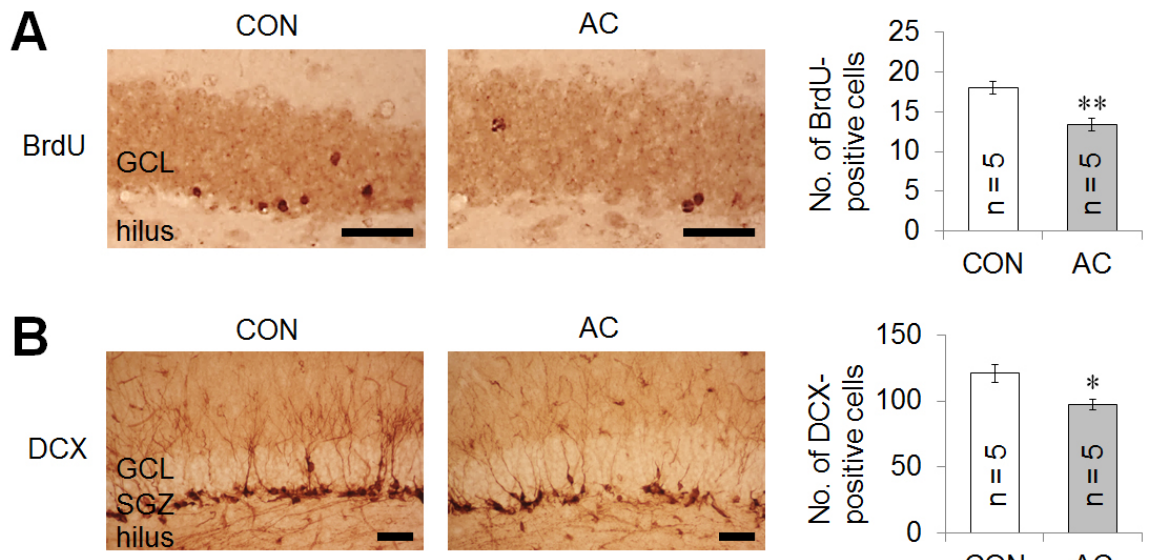

Fig. 6. AC affected hippocampal neurogenesis. Representative DG immunohistochemical sections at 4 weeks following injection with vehicleor AC-treated group. (A) BrdU and (B) DCX immunostaining. The number of BrdU- or DCX-positive cells in the DG was significantly decreased 4 weeks after AC treatment. Scale bars represent $50 \mu \mathrm{m}$. Data are expressed as means \pm SEs. ${ }^{*} p<0.05,{ }^{* *} \mathrm{p}<0.01$ vs. vehicle-treated controls. GCL, granular cell layer; SGZ, subgranular zone.
There were significant differences in the CA1 basal dendrites in terms of both the thin and mushroom spines between the vehicleand AC-treated groups 4 weeks after the last injection. AC treatment significantly decreased the proportion of mushroom spines $(t(88)=2.915, \mathrm{p}<0.01$; Fig. $5 \mathrm{~A}$ right $)$, but conversely, the proportion of thin spines was significantly increased $(\mathrm{t}(75.058)=-3.380$, $\mathrm{p}<0.01$; Fig. $5 \mathrm{~A}$ right). No significant differences in the proportion of stubby spines were observed between the vehicle- and ACtreated groups $(\mathrm{t}(88)=0.639, \mathrm{p}=0.524$; Fig. $5 \mathrm{~A}$ right $)$. In the CA1 apical dendrites, there was a significant decrease in the proportion of mushroom spines $(\mathrm{t}(88)=2.572, \mathrm{p}<0.05$; Fig. $5 \mathrm{~B}$ right $)$, but conversely, there was a significant increase in the proportion of thin spines $(\mathrm{t}(88)=-2.718, \mathrm{p}<0.01$; Fig. 5B right). No significant differences were observed between the vehicle- and AC-treated groups in the proportion of stubby spines $(\mathrm{t}(88)=0.459, \mathrm{p}=0.647$; Fig. $5 \mathrm{~B}$ right). However, AC treatment did not significantly alter the proportion of spines in the DG (Fig. 5C right).

Arc is activated in the brain in response to various stimuli, and required to generate stably modified synapse and to regulate spinal morphology [31,32]. Thus, to investigate the effects of chronic AC treatment on the spine structure- and synaptic stability-related signaling, Arc mRNA expression was assessed via qRT-PCR. The Arc level was significantly less in the treatment compared to the control group $(\mathrm{t}(10)=4.608, \mathrm{p}<0.01$; Fig. 5D).

\section{Chronic AC treatment significantly decreased BrdU and DCX expression in the hippocampal DG of adult mice}

To examine the effects of AC on adult hippocampal neurogenesis, the levels of BrdU, a marker of newly generated cells, and DCX, a marker of immature progenitor cells, were semiquantitatively evaluated in the DG of hippocampi after chronic AC treatment. The number of BrdU-positive cells in the DG was markedly decreased 4 weeks following the last injection with $\mathrm{AC}(\mathrm{t}(8)=4.017$, $\mathrm{p}<0.01$; Fig. 6A). The number of DCX-positive cells in the DG was also significantly decreased 4 weeks following the last injection $(t(8)=2.965$, $p<0.05$; Fig. 6B).

\section{Chronic AC treatment reduced hippocampal vascular network}

Blood vessels were detected using vWF immunohistochemistry in brain sections. Fig. 7C shows representative photomicrographs of the immunoreactivity of VWF in vehicle- and AC-treated mouse hippocampi. Our subsequent assessment of vWF immunostaining intensity in the CA1 and DG areas showed that the relative OD values in the $\mathrm{CA1}(\mathrm{t}(8)=2.838, \mathrm{p}<0.05$; Fig. $7 \mathrm{~B}, \mathrm{C})$ and DG $(t(8)=2.902, p<0.05$; Fig. $7 B, C)$ were significantly decreased after chronic AC treatment.

Additionally, VEGF and EPO play important roles in brain angiogenesis [33, 34]. The VEGF protein level was significantly decreased in the hippocampus after chronic AC treatment $(t(12)=2.373, p<0.05$; Fig. 7D left and middle). Similarly, chronic AC treatment significantly reduced the EPO level in the hippocampus ( $t(12)=3.152, \mathrm{p}<0.01$; Fig. $7 \mathrm{D}$ left and right). These data suggest that chronic AC treatment markedly decreased the basal hippocampal vasculature in the mouse hippocampus.

\section{Chronic AC treatment did not activate glial markers in the mouse hippocampus}

To explore microglial changes after AC treatment, the intensity of Ibal (a microglial marker) was evaluated both immunohistochemically and via immunoblotting (Fig. 8A, B). Fig. 8B (left) shows a representative photograph of Ibal-positive cell distribution in the hippocampal DG after AC treatment. No significant difference in the intensity of Ibal-immunopositive cells was apparent between the vehicle- and AC-treated groups $(\mathrm{t}(8)=0.041, \mathrm{p}=0.968$; Fig. $8 \mathrm{C}$ left), consistent with the results of hippocampal Ibal immunoblotting $(\mathrm{t}(4.605)=1.053, \mathrm{p}=0.345$; Fig. $8 \mathrm{~A})$, suggesting that $\mathrm{AC}$ treat- 
A

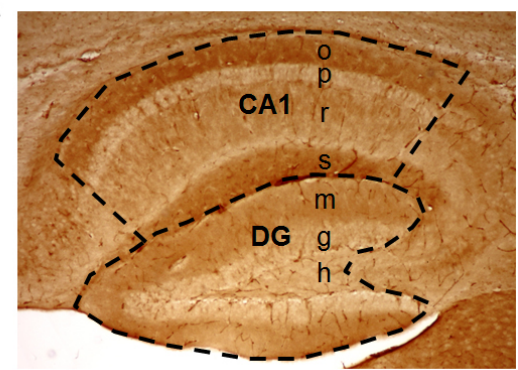

B



C
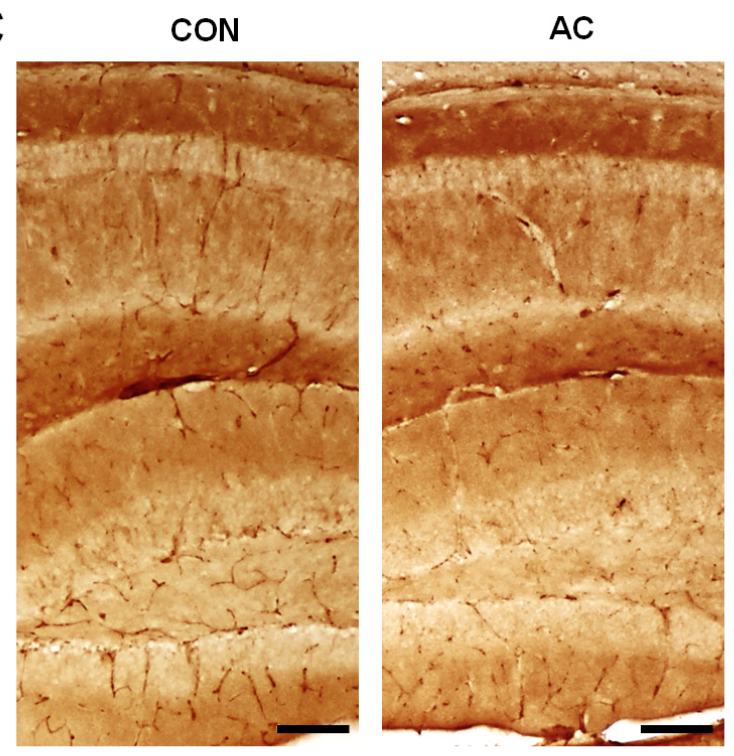

D

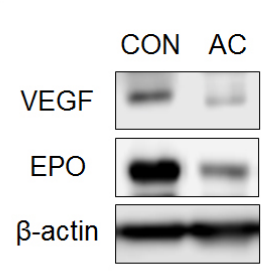

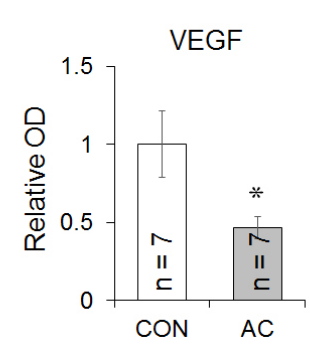

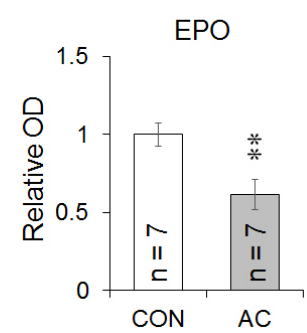

Fig. 7. AC affected the vascular network in the hippocampus. (A) Schematic diagram showing the hippocampal subdivision for intensity measurement (CA1 and DG). (B) Quantification of the vWF-positive fractional vascular area in the CA1 and DG. Results are expressed as the relative OD of the CA1 and DG occupied by blood vessels. (C) Representative microphotographs of the CA1 and DG immunostained for vWF. The expression level of vWF-positive cells in the CA1 and DG were significantly decreased 4 weeks after AC treatment. Scale bar corresponds to 100 $\mu \mathrm{m}$. (D) Changes in protein levels of VEGF and $\mathrm{EPO}$ in the mouse hippocampus after AC injection. Immunoblots were evaluated by measuring the $\mathrm{OD}$, and the signals were normalized to $\beta$-actin. Animals in the AC group showed lower blood vessel density and VEGF and EPO protein levels than vehicle-treated group. Data are expressed as means \pm SEs. ${ }^{*} \mathrm{p}<0.05,{ }^{* *} \mathrm{p}<0.01 \mathrm{vs}$. vehicle-treated controls. ment did not alter Ibal hippocampal protein expression.

Next, the hippocampal protein level of GFAP, an astrocyte marker, was evaluated after AC treatment. Immunoblotting showed that GFAP expression fell after treatment $(t(4.211)=2.725, p=0.05$; Fig. 8A). A representative photograph of GFAP-positive cells in the hippocampal DG after AC treatment (Fig. 8B right) showed that the intensity of GFAP-positive astrocytes also fell after treatment $(\mathrm{t}(8)=4.036$, $\mathrm{p}<0.01$; Fig. $8 \mathrm{C}$ right $)$, suggesting that $\mathrm{AC}$ treatment reduced hippocampal GFAP protein expression.

\section{Chronic AC treatment did not affect hippocampal or serum pro-inflammatory cytokine levels}

To assess the hippocampal inflammatory response to chronic chemotherapy, we measured the levels of mRNAs encoding TNF- $\alpha$, IL-6, IL-1 $\beta$, iNOS, and CD206 via qRT-PCR 4 weeks after the final treatment. The levels of all pro-inflammatory cytokines (TNF- $\alpha$, IL-6, and IL-1 $\beta$ ), the M1 marker (iNOS), and the M2 marker (CD206), were similar in the vehicle- and AC-treated groups (Fig. 9A).

Additionally, pro-inflammatory cytokine levels in hippocampal lysates (Fig. 9B) and plasma (Fig. 9C) were measured to explore changes in peripheral inflammatory responses after AC treatment. However, the levels of TNF- $\alpha$, IL- 6 , and IL- $1 \beta$ did not differ significantly between the groups (Fig. 9B, C), suggesting that hippocampal dysfunction after chronic AC treatment was not associated with a change in inflammatory cytokine levels in either the 
A

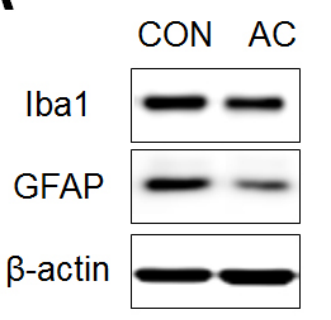

lba1

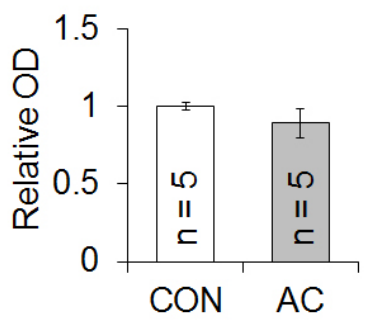

GFAP

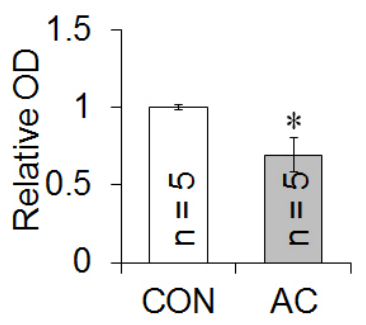

B

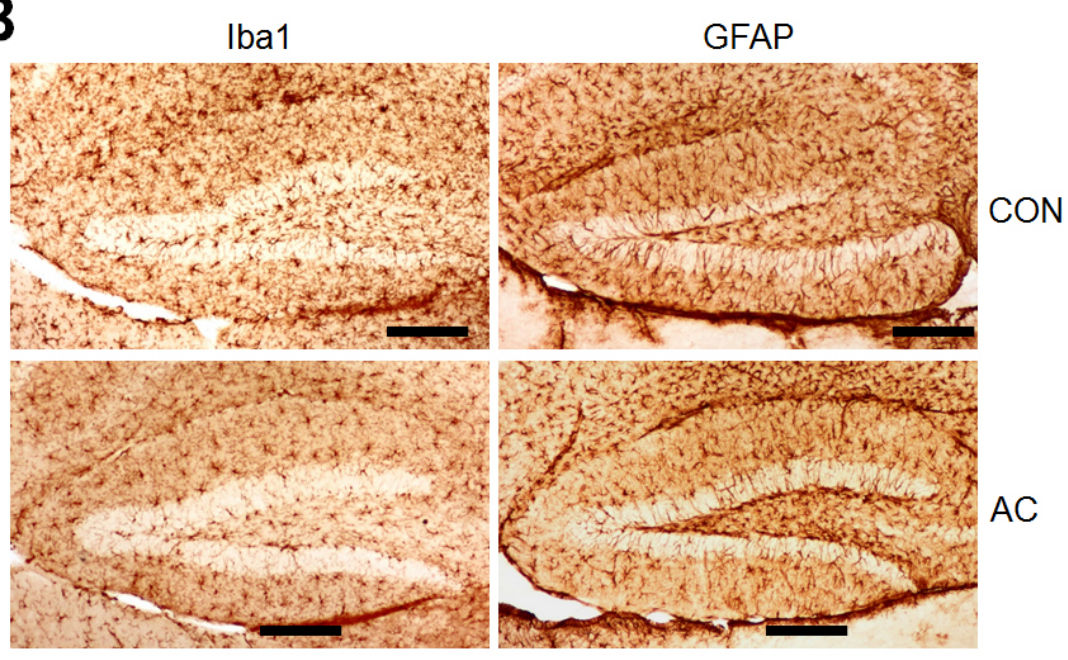

C

Iba1

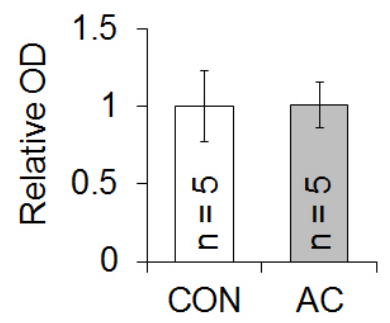

GFAP

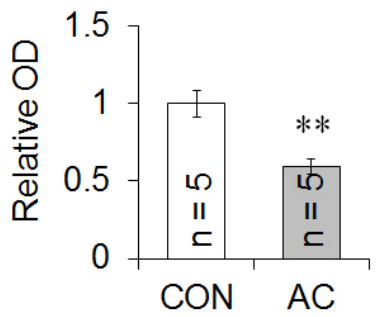

Fig. 8. AC treatment did not up-regulate the levels of certain glial cell proteins. (A) Immunoblots of Ibal and GFAP were evaluated by measuring ODs, and the signals normalized to those of $\beta$-actin. (B) Representative microphotographs of the DG immunostained for Ibal and GFAP. Scale bar: $200 \mu \mathrm{m}$. (C) Quantification of Ibal - and GFAP-positive fractional areas in the DG. The results are expressed as relative ODs. AC treatment did not affect Ibal protein levels, but decreased GFAP protein levels in immunoblots, consistent with the immunohistochemical results. Data are expressed as means \pm SEs. ${ }^{*} \mathrm{p}<0.05,{ }^{* *} \mathrm{p}<0.001$ vs. vehicle-treated controls. hippocampus or the periphery.

\section{DISCUSSION}

The present study demonstrated that chronic treatment with the AC combination induces memory deficit and depression-like behavior in adult mice. AC treatment also significantly altered neuronal architecture (i.e., dendritic ramification, length, and complexity and spine density and maturation) in the adult hippocampus. Additionally, chronic AC treatment reduced hippocampal neurogenesis, basal vasculature, and angiogenesis-related signals, but not increased inflammatory-related signals in adult mice.

Several clinical studies have shown that breast cancer patients who received chronic AC chemotherapy exhibited cognitive im- pairment in domains including visuospatial skills, informationprocessing speed, attention, concentration, and memory, compared to those of age-matched groups who did not receive chemotherapy $[4,5]$. Previous studies using rodent models reported that chronic treatment with the AC combination induced memory impairments related in passive avoidance and contextual fear conditioning $[7,14]$. In the present study, we also found AC-induced cognitive deficits in ORM following chronic AC treatment, indicating that this type of chemotherapy induced cognitive dysfunction in adult mice. Furthermore, chemotherapy may be associated with depression $[35,36]$. For example, in experimental animals, single or repeat exposures to adriamycin significantly induced depression-like behavior in the FST $[6,37]$. Similar to previous studies, the present study also found remarkable depression-like 



Fig. 9. Chronic AC treatment did not affect the levels of inflammation-related signals. (A) Changes in the levels of mRNAs encoding hippocampal TNF- $\alpha$, IL-6, IL-1 $\beta$, iNOS, and CD206. (B) Changes in the levels of TNF- $\alpha$, IL-6, and IL-1 $\beta$ in hippocampal lysates and (C) sera. No mRNA or cytokine level changed following chronic AC treatment. Data are expressed as means \pm SEs.

behaviors in the TST and FST in adult mice after chronic AC treatment. Therefore, chronic AC treatment may induce hippocampusrelated behavioral dysfunction, including cognitive impairment and depression-like behavior.

Neuronal structural plasticity reflects synaptic strength, including dendritic complexity and spine density and morphology, and thus regulates brain functions [38, 39]. A previous study reported a regression in dendritic complexity and spine density/morphology under several conditions associated with neurological changes, such as aging, Alzheimer's disease, and cranial irradiation [27, 29]. Previous studies have established a negative impact of anti-cancer agents on dendritic branching and spine density and morphology under several treatment conditions (e.g., acute/chronic, once/ repeat, and single/combination treatments) $[22,40]$. A low dose of cisplatin has negative effects on synaptic stability and dendrite and spine morphology in cultured hippocampal neurons, and the dendritic complexity and spine density were reduced in the hippocampi of young Sprague-Dawley rats at 3 days after 2 days of in- jections [40]. Groves et al. [22] (2017) found significant changes in the dendritic lengths and numbers of branch points 1 month after chronic 5-fluorouracil treatment, indicating a reduction in dendritic complexity. In this study, the total dendritic length, branch points, and complexity in the CA1 apical and DG dendrites of adult mice were significantly reduced by chronic AC treatment.

Dendritic spines protruding from dendrites constitute the postsynaptic compartments of most excitatory synapses; their density and morphology reflect synaptic strength. For example, dendritic spine density in the CAl was increased when rats were trained using the trace eyeblink conditioning paradigm [41]. However, research using an Alzheimer's disease model supported a role for impaired synaptic plasticity in dendritic spine loss [42]. Additionally, Arc, an immediate-early gene, is transiently and rapidly activated in the brain in response to various physiological and pathological stimuli. Arc synthesis is necessary for early expression of LTP, and sustained Arc synthesis is required to generate stably modified synapses [31]. Arc increases spinal density and regulates 
spinal morphology by increasing the proportion of thin spines. Thus, Arc mutants fail to increase that proportion, and loss of Arc in vivo significantly decreases the proportion [32]. In the present study, chronic AC treatment decreased the level of mRNA encoding hippocampal Arc, spinal density, and the proportion of mushroom spines in the dendrites of CAl pyramidal neurons. These results are consistent with those of previous studies showing that chronic chemotherapy (5-fluorouracil or cyclophosphamide) significantly decreased dendritic spine density and the proportion of mature spines [20,22]. Consequently, changes in neuronal architecture (i.e., dendritic complexity and arborization; spine density and morphology) in the hippocampus via down-regulation of Arc may be related to the cognitive deficit in ORM and the depressionlike behavior observed after chronic AC chemotherapy, possibly reflecting weakening of the synapses.

Hippocampal neurogenesis is related to the control of memory and mood state [43]. Exposure to anti-cancer agents, including cyclophosphamide and methotrexate, inhibits hippocampal neurogenesis and alters hippocampus-related behaviors, such as those involving memory and depression $[8,36,44]$. Our current results extend these previous findings by showing that chronic AC treatment decreased the numbers of BrdU (a proliferating cell marker)and DCX (immature progenitor neuron)-positive cells in the DG of adult hippocampi 4 weeks after the cessation of treatment. This suggests that chronic AC treatment persistently suppresses the generation of new neural cells and the maturation of hippocampal cells in the DG of the adult hippocampus. Furthermore, decreased neurogenesis reflects the abnormal dendritic morphology of the DG in chronic chemotherapy-treated animal models [26, 45]. Thus, these chemotherapy-induced alterations may affect hippocampal functioning including memory and emotional regulation.

The cerebrovascular system plays important roles in supporting the brain by providing it with oxygen and nutrients. Abnormalities occurring in the cerebral vasculature may affect the integrity of brain structuring and functioning [34]. Some anti-cancer agents (e.g., methotrexate and cisplatin) that can directly cross the bloodbrain barrier (BBB) have detrimental effects on brain functions [19, $46,47]$. However, most other anti-cancer agents (e.g., doxorubicin (adriamycin), cyclophosphamide, and 5-fluorouracil) cannot cross the BBB [48]. Nonetheless, even if the anti-cancer agent cannot cross the BBB, it can activate the immune system by releasing pro-inflammatory cytokines, such as TNF- $\alpha$, which itself crosses the $\mathrm{BBB}$, leading to increased reactive oxygen species (ROS) and inflammation [26]. Indeed, adriamycin [49] and cyclophosphamide [50] were shown to induce lipid peroxidation and generation of ROS, respectively, which are the main causes of neurotoxicity in experimental animals. There is a consensus that increased lev- els of ROS damage elements that are essential for neurovascular formation [51]. These ROS and cytokines damage blood vessels or reduce cerebral blood flow, and these damages can alter neuronal structure and cognitive impairment [52]. Thus, chronic ACinduced hippocampal dysfunction may be related to reductions in neurovascular formation. In this study, the vWF-immunoreactive area in the hippocampus of AC-treated mice corresponding to blood vessels was smaller than that in vehicle-treated mice. Indeed, previous studies have reported that diabetes-induced downregulation of the vascular area in the granular cell layer may be related to the cell proliferation, cell survival, dendritic ramification, dendritic length, and spine density of hippocampal neurons [53]. Thus, our data suggest that the reduced neurovasculature, which is functionally related to plasticity and neuronal maintenance, may be involved in the hippocampus-related impairments following chronic AC treatment.

VEGF is known for its role in controlling both vasculogenesis and angiogenesis [34], and it has also emerged as a factor involved in neuroprotection and adult neurogenesis via its stimulation of endothelial cells to release neurotrophic signals [54]. A previous study showed that hippocampal VEGF overexpression enhanced spatial memory in the Morris water maze test and passive avoidance task and also enhanced adult neurogenesis in the rat brain [55]. However, loss of function of VEGF reduces the spine density of newborn granule cells and the dendritic length of periglomerular cells in the olfactory bulb, indicating that VEGF is important for the proper dendritogenesis and dendritic spine formation of newly generated olfactory bulb interneurons [56]. In this study, we observed a significant decrease in the protein level of hippocampal VEGF along with reductions in dendritic spine density, adult neurogenesis, and the neurovascular network following chronic AC treatment. EPO, which is associated with the regulation of red blood cell production, can promote angiogenesis and endothelial cell proliferation [33]. Recently, it has been proposed that EPO plays a role in neurotrophic and neuroprotective processing, and it can enhance antioxidant enzyme expression and reduce free radical production in the central nervous system [57]. EPO also enhances neurite outgrowth and spine formation in the hippocampus [33]. In the present study, we found that chronic AC treatment also decreased EPO levels the hippocampus. Consequently, it is suggested that chronic AC treatment suppressed the expression of both VEGF and EPO, resulting in hippocampal dysfunction, possibly through alteration of neurogenesis, the neurovasculature, and the neuronal architecture.

Microglia and astrocytes are activated in various neurodegenerative diseases including Parkinson's disease, Alzheimer's disease, prion-caused diseases, multiple sclerosis, and human immuno- 
deficiency virus-associated dementia [58]. In animal models of Alzheimer's disease, activated astrocytes exhibit increased levels of GABA release, in turn inhibiting synaptic plasticity and causing memory impairment [59]. Activated microglia and astrocytes may play potentially detrimental roles by eliciting the expression of pro-inflammatory cytokines [60]. One clinical study found that chemotherapy increased the serum levels of pro-inflammatory cytokines including IL-1 $\beta$, TNF- $\alpha$, and IL-6, causing anorexia, cachexia, anemia, pain, sleep disturbance, fatigue, and depression [61]. Furthermore, one animal study suggested that methotrexateinduced cognitive deficits were caused by increased microglial expression, and upregulation, of iNOS and cyclooxygenase-2 levels on day 1 post-treatment [62]. Another report showed that 5 -fluorouracil treatment also up-regulated the levels of pro- and anti-inflammatory cytokines in the mouse brain, and compromised dendritic architecture (dendritic complexity, spinal density, and maturation) [22]. However, chemotherapy is not always accompanied by elevations in the levels of inflammation-related factors. Clinically, breast cancer patients who received chemotherapy exhibited cognitive impairment, but no significant correlation was apparent between their symptoms and cytokine levels, compared to those of an age-matched group who did not receive chemotherapy [63]. In addition, Seigers et al. [64] (2010) reported that the cytokine levels in plasma and homogenized hippocampal tissue were reduced after methotrexate treatment, but activated microglia were observed in the hippocampus. In the present study, the hippocampal level of Iba1-positive microglia did not change following chronic AC treatment. Furthermore, the levels of pro-inflammatory cytokines and M1/M2 cell markers, including TNF- $\alpha$, IL-6, IL$1 \beta$, iNOS, and CD206, did not change after chronic AC treatment. GFAP protein expression decreased significantly 4 weeks after AC treatment, indicating that neuroinflammation was not essential for the development of chronic chemotherapy-induced hippocampal dysfunction. The differences in the inflammatory response to chemotherapy among studies may be explained by physiological differences among rodent strains, and variations in the therapeutic regimens (drugs, dosages, and treatment durations and timings). Further studies using a well-controlled experimental paradigm to mimic clinical chemotherapy are required to explore the correlations between neuroinflammation and chemotherapy.

As mentioned above, we found that GFAP activity fell in response to chronic AC treatment. Astrocytic processes contact neurons and interact with neuron; the motility of astrocytic processes reflects structural modulation of the neural dendritic spines. Under normal conditions, stimuli that induce the hippocampal synaptic LTP enhance the motility of astrocytic processes, which then envelop synaptic terminals (the dendritic spines) to contrib- ute to the maturation of those spines [65]. However, disruption of astrocytic process motility via manipulation of Rac1-dependent signaling increases the synthesis of long filopodium-like dendritic spines (which are immature). In addition, disruption of the adhesion between astrocytes and neurons via an ephrin/Eph blockade destabilized newly generated dendritic spines [66]. Furthermore, astrocytes and cerebral vascular endothelial cells constitute neurovascular units in which the astrocytes act as cellular bridges between the blood vessels and neurons [67]. If the connectivity of astrocytic processes is weakened, neurons cannot receive nutrients from the vascular network. In Alzheimer's disease, overproduction of amyloid plaques triggers changes in astrocytes, inducing blood vessel constriction [68]. Therefore, down-regulation of astrocytic expression following chronic AC treatment (as evident in the present study) may weaken the network that features both neurons and their supply vessels, followed by abnormal dendritic spine morphogenesis and spinal destabilization. Although such weakening may explain the observed reduction in GFAP protein level, further studies are needed to confirm the changes in astrocytic processes following chemotherapy.

In conclusion, we found that chronic AC chemotherapy impaired hippocampal functioning by altering the neuronal architecture of the hippocampus. The observed reductions in the extent of the neurovascular network and the astrocyte distribution were consistent with the observed damage to neuronal structures and neurogenesis after chemotherapy; inflammatory hippocampal signals were not involved. Therefore, micromorphometric changes may explain the hippocampal dysfunction developing after chronic chemotherapy, independently of neuroinflammation.

\section{ACKNOWLEDGEMENTS}

This work was supported by Chonnam National University (2017-2770) and National Research Foundation (NRF) of Korea grant funded by the Korean Government (NRF-2016R1D1A1B03933836).

\section{REFERENCES}

1. Ahles TA, Saykin AJ (2002) Breast cancer chemotherapyrelated cognitive dysfunction. Clin Breast Cancer 3 Suppl 3:S84-S90.

2. James SE, Burden H, Burgess R, Xie Y, Yang T, Massa SM, Longo FM, Lu Q (2008) Anti-cancer drug induced neurotoxicity and identification of Rho pathway signaling modulators as potential neuroprotectants. Neurotoxicology 29:605-612.

3. Pandey M, Sarita GP, Devi N, Thomas BC, Hussain BM, 
Krishnan R (2006) Distress, anxiety, and depression in cancer patients undergoing chemotherapy. World J Surg Oncol 4:68.

4. Deprez S, Amant F, Smeets A, Peeters R, Leemans A, Van Hecke W, Verhoeven JS, Christiaens MR, Vandenberghe J, Vandenbulcke M, Sunaert S (2012) Longitudinal assessment of chemotherapy-induced structural changes in cerebral white matter and its correlation with impaired cognitive functioning. J Clin Oncol 30:274-281.

5. Jansen CE, Dodd MJ, Miaskowski CA, Dowling GA, Kramer J (2008) Preliminary results of a longitudinal study of changes in cognitive function in breast cancer patients undergoing chemotherapy with doxorubicin and cyclophosphamide. Psychooncology 17:1189-1195.

6. Merzoug S, Toumi ML, Tahraoui A (2014) Quercetin mitigates Adriamycin-induced anxiety- and depression-like behaviors, immune dysfunction, and brain oxidative stress in rats. Naunyn Schmiedebergs Arch Pharmacol 387:921-933.

7. Konat GW, Kraszpulski M, James I, Zhang HT, Abraham J (2008) Cognitive dysfunction induced by chronic administration of common cancer chemotherapeutics in rats. Metab Brain Dis 23:325-333.

8. Yang M, Kim JS, Kim J, Kim SH, Kim JC, Kim J, Wang H, Shin T, Moon C (2011) Neurotoxicity of methotrexate to hippocampal cells in vivo and in vitro. Biochem Pharmacol 82:72-80.

9. Seigers R, Fardell JE (2011) Neurobiological basis of chemotherapy-induced cognitive impairment: a review of rodent research. Neurosci Biobehav Rev 35:729-741.

10. Myers JS (2009) Chemotherapy-related cognitive impairment. Clin J Oncol Nurs 13:413-421.

11. Tannock IF, Ahles TA, Ganz PA, Van Dam FS (2004) Cognitive impairment associated with chemotherapy for cancer: report of a workshop. J Clin Oncol 22:2233-2239.

12. Anampa J, Makower D, Sparano JA (2015) Progress in adjuvant chemotherapy for breast cancer: an overview. BMC Med 13:195.

13. Goldhirsch A, Wood WC, Gelber RD, Coates AS, Thürlimann B, Senn HJ (2003) Meeting highlights: updated international expert consensus on the primary therapy of early breast cancer. J Clin Oncol 21:3357-3365.

14. Macleod JE, DeLeo JA, Hickey WF, Ahles TA, Saykin AJ, Bucci DJ (2007) Cancer chemotherapy impairs contextual but not cue-specific fear memory. Behav Brain Res 181:168-172.

15. Parihar VK, Limoli CL (2013) Cranial irradiation compromises neuronal architecture in the hippocampus. Proc Natl Acad Sci U S A 110:12822-12827.

16. Sebastian V, Estil JB, Chen D, Schrott LM, Serrano PA (2013) Acute physiological stress promotes clustering of synaptic markers and alters spine morphology in the hippocampus. PLoS One 8:e79077.

17. Tronel S, Fabre A, Charrier V, Oliet SH, Gage FH, Abrous DN (2010) Spatial learning sculpts the dendritic arbor of adult-born hippocampal neurons. Proc Natl Acad Sci U S A 107:7963-7968.

18. Magariños AM, Li CJ, Gal Toth J, Bath KG, Jing D, Lee FS, McEwen BS (2011) Effect of brain-derived neurotrophic factor haploinsufficiency on stress-induced remodeling of hippocampal neurons. Hippocampus 21:253-264.

19. Zhou W, Kavelaars A, Heijnen CJ (2016) Metformin prevents cisplatin-induced cognitive impairment and brain damage in mice. PLoS One 11:e0151890.

20. Acharya MM, Martirosian V, Chmielewski NN, Hanna N, Tran KK, Liao AC, Christie LA, Parihar VK, Limoli CL (2015) Stem cell transplantation reverses chemotherapy-induced cognitive dysfunction. Cancer Res 75:676-686.

21. Kesler S, Janelsins M, Koovakkattu D, Palesh O, Mustian K, Morrow G, Dhabhar FS (2013) Reduced hippocampal volume and verbal memory performance associated with interleukin-6 and tumor necrosis factor-alpha levels in chemotherapy-treated breast cancer survivors. Brain Behav Immun 30 Suppl:S109-S116.

22. Groves TR, Farris R, Anderson JE, Alexander TC, Kiffer F, Carter G, Wang J, Boerma M, Allen AR (2017) 5-Fluorouracil chemotherapy upregulates cytokines and alters hippocampal dendritic complexity in aged mice. Behav Brain Res 316:215224.

23. Alexander TC, Simecka CM, Kiffer F, Groves T, Anderson J, Carr H, Wang J, Carter G, Allen AR (2018) Changes in cognition and dendritic complexity following intrathecal methotrexate and cytarabine treatment in a juvenile murine model. Behav Brain Res 346:21-28.

24. Son Y, Yang M, Kim JS, Kim J, Kim SH, Kim JC, Shin T, Wang H, Jo SK, Jung U, Moon C (2014) Hippocampal dysfunction during the chronic phase following a single exposure to cranial irradiation. Exp Neurol 254:134-144.

25. Flanigan TJ, Anderson JE, Elayan I, Allen AR, Ferguson SA (2018) Effects of cyclophosphamide and/or doxorubicin in a murine model of postchemotherapy cognitive impairment. Toxicol Sci 162:462-474.

26. Christie LA, Acharya MM, Parihar VK, Nguyen A, Martirosian V, Limoli CL (2012) Impaired cognitive function and hippocampal neurogenesis following cancer chemotherapy. Clin Cancer Res 18:1954-1965.

27. Morley BJ, Mervis RF (2013) Dendritic spine alterations in the hippocampus and parietal cortex of alpha7 nicotinic ace- 
tylcholine receptor knockout mice. Neuroscience 233:54-63.

28. Sholl DA (1953) Dendritic organization in the neurons of the visual and motor cortices of the cat. J Anat 87:387-406.

29. Chakraborti A, Allen A, Allen B, Rosi S, Fike JR (2012) Cranial irradiation alters dendritic spine density and morphology in the hippocampus. PLoS One 7:e40844.

30. Kang S, Son Y, Lee S, Kim J, Kim JC, Kim JS, Jung U, Kim SH, Yang M, Moon C (2017) Changes in epigenetic markers, DNMT1 and HDAC1/2, in the adult mouse hippocampus after cranial irradiation. Neurosci Lett 657:113-119.

31. Messaoudi E, Kanhema T, Soulé J, Tiron A, Dagyte G, da Silva B, Bramham CR (2007) Sustained Arc/Arg3.1 synthesis controls long-term potentiation consolidation through regulation of local actin polymerization in the dentate gyrus in vivo. J Neurosci 27:10445-10455.

32. Peebles CL, Yoo J, Thwin MT, Palop JJ, Noebels JL, Finkbeiner S (2010) Arc regulates spine morphology and maintains network stability in vivo. Proc Natl Acad Sci U S A 107:1817318178 .

33. Noguchi CT, Asavaritikrai P, Teng R, Jia Y (2007) Role of erythropoietin in the brain. Crit Rev Oncol Hematol 64:159171.

34. Chen CC, Chen YC, Hsiao HY, Chang C, Chern Y (2013) Neurovascular abnormalities in brain disorders: highlights with angiogenesis and magnetic resonance imaging studies. J Biomed Sci 20:47.

35. Callari A, Mauri M, Miniati M, Mancino M, Bracci G, Dell'Osso L, Greco C (2013) Treatment of depression in patients with breast cancer: a critical review. Tumori 99:623-633.

36. Yang M, Moon C (2015) Effects of cancer therapy on hippocampus-related function. Neural Regen Res 10:1572-1573.

37. Wu YQ, Dang RL, Tang MM, Cai HL, Li HD, Liao DH, He X, Cao LJ, Xue Y, Jiang P (2016) Long chain omega-3 polyunsaturated fatty acid supplementation alleviates doxorubicininduced depressive-like behaviors and neurotoxicity in rats: involvement of oxidative stress and neuroinflammation. Nutrients 8:243.

38. Kasai H, Matsuzaki M, Noguchi J, Yasumatsu N, Nakahara H (2003) Structure-stability-function relationships of dendritic spines. Trends Neurosci 26:360-368.

39. Dailey ME, Smith SJ (1996) The dynamics of dendritic structure in developing hippocampal slices. J Neurosci 16:29832994.

40. Andres AL, Gong X, Di K, Bota DA (2014) Low-doses of cisplatin injure hippocampal synapses: a mechanism for 'chemo' brain? Exp Neurol 255:137-144.

41. Leuner B, Falduto J, Shors TJ (2003) Associative memory formation increases the observation of dendritic spines in the hippocampus. J Neurosci 23:659-665.

42. Lazcano Z, Solis O, Bringas ME, Limón D, Diaz A, Espinosa B, García-Peláez I, Flores G, Guevara J (2014) Unilateral injection of $A \beta_{25-35}$ in the hippocampus reduces the number of dendritic spines in hyperglycemic rats. Synapse 68:585-594.

43. Becker S, Wojtowicz JM (2007) A model of hippocampal neurogenesis in memory and mood disorders. Trends Cogn Sci 11:70-76.

44. Albert RE, Deal BJ (1991) Program planning for the certified emergency nursing review course. J Emerg Nurs 17:108-111.

45. Nokia MS, Anderson ML, Shors TJ (2012) Chemotherapy disrupts learning, neurogenesis and theta activity in the adult brain. Eur J Neurosci 36:3521-3530.

46. Yang M, Moon C (2013) Neurotoxicity of cancer chemotherapy. Neural Regen Res 8:1606-1614.

47. Myers JS, Pierce J, Pazdernik T (2008) Neurotoxicology of chemotherapy in relation to cytokine release, the bloodbrain barrier, and cognitive impairment. Oncol Nurs Forum 35:916-920.

48. Juillerat-Jeanneret L (2008) The targeted delivery of cancer drugs across the blood-brain barrier: chemical modifications of drugs or drug-nanoparticles? Drug Discov Today 13:10991106.

49. Joshi G, Sultana R, Tangpong J, Cole MP, St Clair DK, Vore M, Estus S, Butterfield DA (2005) Free radical mediated oxidative stress and toxic side effects in brain induced by the anti cancer drug adriamycin: insight into chemobrain. Free Radic Res 39:1147-1154.

50. Bhatia AL, Manda K, Patni S, Sharma AL (2006) Prophylactic action of linseed (Linum usitatissimum) oil against cyclophosphamide-induced oxidative stress in mouse brain. J Med Food 9:261-264.

51. Chrissobolis S, Faraci FM (2008) The role of oxidative stress and NADPH oxidase in cerebrovascular disease. Trends Mol Med 14:495-502.

52. Liu H, Zhang J (2012) Cerebral hypoperfusion and cognitive impairment: the pathogenic role of vascular oxidative stress. Int J Neurosci 122:494-499.

53. Beauquis J, Roig P, De Nicola AF, Saravia F (2010) Short-term environmental enrichment enhances adult neurogenesis, vascular network and dendritic complexity in the hippocampus of type 1 diabetic mice. PLoS One 5:e13993.

54. Louissaint A Jr, Rao S, Leventhal C, Goldman SA (2002) Coordinated interaction of neurogenesis and angiogenesis in the adult songbird brain. Neuron 34:945-960.

55. Cao L, Jiao X, Zuzga DS, Liu Y, Fong DM, Young D, During 
MJ (2004) VEGF links hippocampal activity with neurogenesis, learning and memory. Nat Genet 36:827-835.

56. Licht T, Eavri R, Goshen I, Shlomai Y, Mizrahi A, Keshet E (2010) VEGF is required for dendritogenesis of newly born olfactory bulb interneurons. Development 137:261-271.

57. Dale EA, Mitchell GS (2013) Spinal vascular endothelial growth factor (VEGF) and erythropoietin (EPO) induced phrenic motor facilitation after repetitive acute intermittent hypoxia. Respir Physiol Neurobiol 185:481-488.

58. Dheen ST, Kaur C, Ling EA (2007) Microglial activation and its implications in the brain diseases. Curr Med Chem 14:1189-1197.

59. Jo S, Yarishkin O, Hwang YJ, Chun YE, Park M, Woo DH, Bae JY, Kim T, Lee J, Chun H, Park HJ, Lee DY, Hong J, Kim HY, Oh SJ, Park SJ, Lee H, Yoon BE, Kim Y, Jeong Y, Shim I, Bae YC, Cho J, Kowall NW, Ryu H, Hwang E, Kim D, Lee CJ (2014) GABA from reactive astrocytes impairs memory in mouse models of Alzheimer's disease. Nat Med 20:886-896.

60. Cheung YT, Lim SR, Ho HK, Chan A (2013) Cytokines as mediators of chemotherapy-associated cognitive changes: current evidence, limitations and directions for future research. PLoS One 8:e81234.

61. Wood LJ, Nail LM, Gilster A, Winters KA, Elsea CR (2006) Cancer chemotherapy-related symptoms: evidence to suggest a role for proinflammatory cytokines. Oncol Nurs Forum 33:535-542.
62. Yang M, Kim JS, Kim J, Jang S, Kim SH, Kim JC, Shin T, Wang H, Moon C (2012) Acute treatment with methotrexate induces hippocampal dysfunction in a mouse model of breast cancer. Brain Res Bull 89:50-56.

63. Booth C, Vardy J, Crawley A, Rourke S, Pond G, Wagner L, Tannock I (2006) Cognitive impairment associated with chemotherapy for breast cancer: an exploratory case-control study. J Clin Oncol 24:8501.

64. Seigers R, Timmermans J, van der Horn HJ, de Vries EF, Dierckx RA, Visser L, Schagen SB, van Dam FS, Koolhaas JM, Buwalda B (2010) Methotrexate reduces hippocampal blood vessel density and activates microglia in rats but does not elevate central cytokine release. Behav Brain Res 207:265-272.

65. Perez-Alvarez A, Navarrete M, Covelo A, Martin ED, Araque A (2014) Structural and functional plasticity of astrocyte processes and dendritic spine interactions. J Neurosci 34:1273812744.

66. Nishida H, Okabe S (2007) Direct astrocytic contacts regulate local maturation of dendritic spines. J Neurosci 27:331-340.

67. Ramos RL, Smith PT, Croll SD, Brumberg JC (2008) Demonstrating cerebral vascular networks: a comparison of methods for the teaching laboratory. J Undergrad Neurosci Educ 6:A53-A59.

68. MacVicar BA, Newman EA (2015) Astrocyte regulation of blood flow in the brain. Cold Spring Harb Perspect Biol 7:a020388. 